Western University Scholarship@Western

Economic Policy Research Institute. EPRI Working

Papers

Economics Working Papers Archive

2007

\title{
2007-1 Equity in Pharmaceutical Utilization in Ontario: A Cross Section and Over Time Analysis
}

Hai Zhong

Follow this and additional works at: https://ir.lib.uwo.ca/economicsepri_wp

Part of the Economics Commons

Citation of this paper:

Zhong, Hai. "2007-1 Equity in Pharmaceutical Utilization in Ontario: A Cross Section and Over Time Analysis." Economic Policy Research Institute. EPRI Working Papers, 2007-1. London, ON: Department of Economics, University of Western Ontario (2007). 
Equity in Pharmaceutical Utilization in Ontario: A Cross Section and Over Time Analysis

by

Hai Zhong

Working Paper \# 2007-1

September 2007

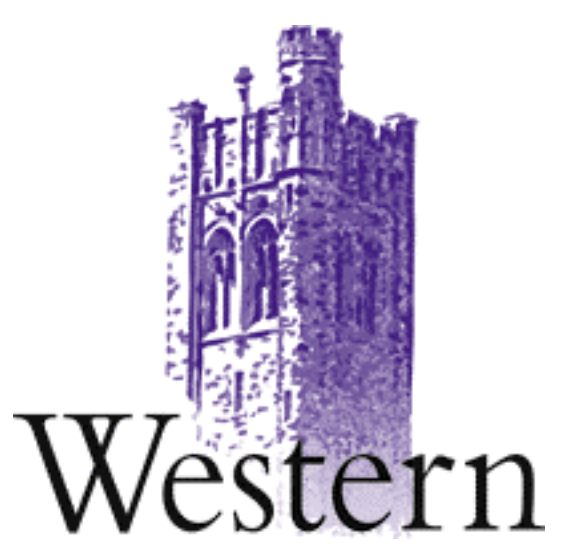

\title{
RBC Financial Group \\ Economic Policy Research Institute EPRI Working Paper Series
}

\author{
Department of Economics \\ Department of Political Science \\ Social Science Centre \\ The University of Western Ontario \\ London, Ontario, N6A 5C2 \\ Canada
}

This working paper is available as a downloadable pdf file on our website http://economics.uwo.ca/centres/epri/ 
Equity in Pharmaceutical Utilization in Ontario: A Cross Section and Over Time Analysis 


\section{HAI ZHONG}

Economic Policy Research Institute

Department of Economics and Department of Political Science The University of Western Ontario

London, Ontario

and

China Academy of Public Finance and Public Policy

Central University of Finance and Economics

Beijing, China

E-mail: haizhong@cufe.edu.cn; Tel: 86-10-62289629 


\begin{abstract}
This study investigates inequality and inequity in pharmaceutical utilization in Ontario. First, I compare inequality and inequity in drug use between senior and non-senior population in Ontario at each of three points in time. During this time period, all seniors in Ontario have been universally covered by the publicly financed OBD program. This is not the case for the non-senior population. Second, I examine the changes in inequality and inequity for each population group at each of the three time points: 1990, 1996/97 and 2000/01. During this period, cost-sharing and other changes were introduced into the ODB, which allows us to identify the influence on equity of changes on drug coverage policies.
\end{abstract}




\section{Introduction}

Most developed countries regard equity in health care access as a crucial element of health system performance. Canada has achieved universal, first-dollar coverage ${ }^{1}$ for its population for a comprehensive package of medically necessary physician and hospital services. However, even under public and universal coverage, the patterns of equity in the utilization of these services vary. For GP and hospital services, most studies (Eyles et al. 1995; Newbold et al. 1995; Van Doorslaer et al. 2002; Van Doorslaer et al. 2004; Van Doorslaer et al. 1992) have found little or no evidence of inequity in access; variations in utilization occur mainly according to need. For specialist services, however, a number of studies (Alter et al. 1999; Van Doorslaer et al. 2002; Van Doorslaer et al. 2004) have found evidence of inequity in access; variations in utilization reflect a strong influence of nonneed factors such as income and education.

Pharmaceutical insurance in out-of-hospital settings is neither universal nor comprehensive within the public health insurance system in Canada. Currently, coverage for prescription drugs in Canada is offered through a mixture of public and private insurance plans. In 2000, 53\% of Canadians were covered by public drug plans, 58\% of Canadians were covered by private drug plans, $13 \%$ of Canadians were covered by both private and public drug plans, and $2 \%$ of Canadians didn’t have any form of drug coverage (Fraser Group and Tristat Resources 2002).

The Canadian Institute for Health Information (2005a) estimates that expenditure on prescribed drugs accounts for 82.5\% of total drug expenditure in Canada in 2004. The nonprescribed drugs are mainly paid by individual out-of-pocket expenditure. For the 
prescribed drugs, the expenditures are shared by public drug insurance plans, private drug insurance plans and individual out-of-pocket payment. In 2002, the public share of spending on prescription drugs was $46.4 \%$. The remaining proportions were paid by private insurers (33.8\%) and patients' out-of-pocket money (19.8\%).

Variation in drug coverage among the Canadian population may lead to inequity in the access to needed medications. Although a few studies (Alan et al. 2002; Alan et al. 2005) have considered the distributional effects of public drug subsidies, no study has evaluated overall equity in drug utilization. However, we need to investigate equity in drug utilization because prescribed drug utilization has become a more and more important component of health care services worldwide. In Canada, between 1975 and 2004, per capita prescribed drug expenditure in Canada has risen from $\$ 119$ to $\$ 562^{2}$; and expenditure on prescribed drugs as a proportion of total health expenditure has increased from $6.3 \%$ to $13.8 \%$ (Canadian Institute for Health Information 2005b). Prescribed drug expenditure has increased at a more rapid rate than any other health care expenditure. Moreover, as drugs are used increasingly as the therapy of choice for many conditions, their potential applications to improve health are expanding rapidly. Because equity in health care access is the goal of most health care systems, when the importance of drug use among health care services goes up, equity in drug utilization is increasingly important for overall system performance.

This study investigates income-related equality and equity in pharmaceutical utilization in Ontario and the influence of public drug insurance on this equality and equity. The fundamental difference between inequity and inequality resides in the fact that inequity represents inequality that is considered and qualified as unjust and avoidable. As a result, 
measuring inequality in pharmaceutical utilization represents the first step towards the identification of inequity in pharmaceutical utilization. This is a two-dimensional study, both cross-sectional and over time, and also across population groups. First, I compare income-related equality and equity in drug use between the senior population and nonsenior population in Ontario at each of three points in time. All seniors in Ontario are universally covered by the publicly financed Ontario Drug Benefit (ODB) program. This is not the case for the non-senior population. Therefore, this difference in coverage provides an opportunity to examine the impact of universal drug coverage on income-related equality and equity in drug utilization. Second, I examine the changes in income-related equality and equity for each population group at each of the three time points: 1990, 1996/97 and 2000/01. During this period, cost-sharing and other changes were introduced into the ODB, which allow us to identify the influence on income-related equality and equity of changes in drug coverage policies.

The analysis proceeds as follows. First, at each time point, I identify whether there exists income-related inequality in observed drug utilization for each population group. Inequality here refers to the degree to which the individuals in an income distribution have shares of drug utilization that are unequal in quantity. Secondly, I measure the incomerelated inequity in drug use. The goal of most health care systems is equity rather than equality. Equity here refers to horizontal equity, namely access to drugs by all people on the basis of need. When the term "access" is used in most empirical studies, it is usually defined as "receipt of treatment". However, access to treatment and receipt of treatment may not be the same thing. The former refers to the opportunities open to people, while the latter is related to the realization of the opportunities. If an individual does not realize the 
opportunities at his or her own will, inequity in access may not be a problem. Since it is difficult to find measures on opportunities open to people in the datasets, I follow most empirical studies by measuring access as receipt of treatment in this analysis. Therefore, for the system being equitable, people with equal need should utilize the same amount of drugs regardless of their income or social economic status. Thirdly, I decompose the inequality into its causes. The decomposition sheds light on the causes of inequity and can inform efforts by policy makers to improve equity in drug utilization. Finally, I compare incomerelated inequality and inequity of drug use between population groups and time points.

In the next section, I briefly introduce drug coverage in Ontario. The third section describes the data and methods that I am going to use. The fourth section presents my results. In the last section, I will draw my conclusions.

\section{Drug Coverage in Ontario}

Coverage for prescription drugs in Ontario is offered through a mixture of public and private insurance plans. In 2000, 62\% of the residents of Ontario were covered by various private drug plans (Fraser Group and Tristat Resources 2002). It is difficult to obtain data on the percentage of Ontarians who were covered by private drug plans in 1990 and 1996/97. However, according to the Canadian Institute for Health Information (2005b), the share of private insurers on prescription drug expenditure in Canada was constantly in the range of $30.2 \%$ to $33.8 \%$ from 1988 to 2002 . Therefore, we can believe that there are no significant changes in the status of private drug coverage in our examining period.

Currently, there are three publicly financed provincial drug insurance programs in operation, administered by the Drug Programs Branch of the Ministry of Health and Long- 
Term Care: the Ontario Drug Benefit (ODB), the Trillium Drug Program (TDP), and the Special Drug Program (SDP).

The target populations of the Ontario Drug Benefit (ODB) program are seniors, residents of long-term care facilities and homes for special service care, and social assistance recipients. All seniors were universally and fully covered (with no co-payments required) by this program from August 1975 to July 14, 1996. From July 15, 1996, single seniors who have an annual income of $\$ 16,018$ or more, and seniors in couples with a combined annual income of $\$ 24,175$ or more pay a $\$ 100$ annual deductible per senior. After paying the deductible, they then pay up to $\$ 6.11$ toward the dispensing fee for each prescription. All the other ODB eligible people may be asked to pay up to $\$ 2$ for each prescription.

The Trillium Drug Program (TDP) is available to all residents of Ontario with valid Ontario Health Insurance (OHIP) who are not eligible for the ODB program. Individuals or families can apply to the Trillium Drug Program if private insurance does not cover $100 \%$ of their prescription drug costs. The program has a deductible that is based on income and family size. The deductible is roughly $4 \%$ of total household income. The TDP is provided as a last resort for those have a high level of out-of-pocket drug expenditure. It provides a protective cap for Ontario residents on drug expenses. The TDP was established in April 1995. After its establishment, the number of TDP applications has grown rapidly over time. From 1996 to 2001, the number of TDP applications increased from 18,172 to 59,599 (Ontario Ministry of Health and Long Term Care 2005).

The Special Drugs Program (SDP) covers the full cost of certain out-patient drugs used in the treatment of specific conditions. For example the program covers many drugs 
for the treatment of cystic fibrosis. To qualify, an individual must have one of the diseases or conditions covered and meet established criteria. Under the program there are no deductibles or co-payments. Eligible people do not have to pay for these treatments. The total public SDP cost increased from $\$ 82.6$ million in 1996/97 to $\$ 107.3$ million in 2000/013 (Ontario Ministry of Health and Long Term Care 2005).

At the first time point (1990) of my study, all seniors in Ontario were universally and fully covered by the ODB program. Around $60 \%$ of non-seniors were protected by various private drug insurances, and a small proportion of non-seniors who received social assistance were also covered by the ODB. ${ }^{4}$ At the last two time points of my study, 1996/97 and 2000/01, all seniors in Ontario were still universally covered by the ODB, but they had to pay a deductible and some co-payments; for the non-seniors, there were two new public financed drug insurance plans: TDP and SDP.

Difference on drug insurance coverage between seniors and non-seniors and the over time policy changes may have the following influences on equality and equity in drug utilization:

- Equality and equity in drug utilization among seniors may be more pro-poor than that among non-seniors.

- The imposition of deductibles and co-payments for seniors in the mid of 1990s might have a negative influence (pro-rich) on equality and equity in drug utilization.

- The implementation of TDP and SDP may have a positive influence (pro-poor) on equality and equity in drug utilization among non-seniors.

In the following analysis, I will examine the above hypotheses. 


\section{Data, Variables and Methods}

To analyze equality and equity in drug utilization, we need individual level information on drug use, income, and other variables that may affect drug use, e.g., gender, age, health status, recent illness and injury, education, immigration status, and additional medical insurance information.

\subsection{Data}

The data for the three time points in this study come from 1990 Ontario Health Survey (OHS), the public use file of 1996/97 National Population Health Survey (NPHS) and the master file of 2000/01 Canadian Community Health Survey (CCHS).

\section{$\underline{\text { OHS } 1990}$}

The 1990 Ontario Health Survey is a comprehensive health survey of the population of Ontario, sampling all 42 public health units that existed at the time. Certain groups such as the homeless, aboriginal people on reserves, and those living in institutions were excluded. The survey was conducted by face-to-face interview from January 1990 to November 1990 (excluding July).

The OHS asked each subject the following question regarding drug utilization: "How many different numbers of prescription drugs have you taken in the last 4 weeks?” Responses to this question form the basis for the measure of drug utilization in this analysis. The OHS also contains measures of health status, socioeconomic status, household and 
demographic information, income, medical insurance, etc., which are necessary for this analysis.

The total sample size for the OHS 1990 is 77,663. To make the analyses comparable over time, the observations between age 1 and age 11 are excluded. The NPHS 1996/97 and CCHS 2000/01 only contain information on drug utilization for people aged 12 and older. The sample size for the non-senior population between age 12 and 64 is 53,820; the sample size for the senior population aged 65 or over is 8,769 .

\section{NPHS 1996/97}

The NPHS 1996/97 is the second cycle of the National Population Health Survey. The National Population Health Survey (NPHS) is designed to collect information related to the health of the Canadian population. It is composed of three component parts: the survey of households; the survey of institutions and the survey of the North.

The household component includes household residents in all provinces, with the principal exclusion of populations on Indian Reserves, Canadian Forces Bases and some remote areas in Quebec and Ontario. This analysis employs the public use file of the Ontario section from the household survey of the NPHS 1996/97. The household survey of the NPHS contains two separate data files: a general micro-data file and a health micro-data file. In each household, some limited information was collected from all household members (general micro-data file); one person in each household was randomly selected for a more in-depth interview (health micro-data file). The health micro-data file contains information about drug utilization for people aged 12 and over. Therefore, my analysis is based on the health micro-data file. 
The NPHS asked each subject 21 questions as whether he or she has taken a particular kind of drug in the past month. A derived variable on "number of different drugs taken in the past month" can be constructed based on those questions, and is the measurement of drug utilization in this analysis. The NPHS also contains measures on health status, socioeconomic status, household and demographic information, income, medical insurance, etc., which are necessary for this analysis.

For the NPHS 1996/97 cycle, the Ontario provincial government provided extra funds so that a larger sample of dwellings could be selected. The purpose of this buy-in was to obtain sufficient sample size to provide reliable cross sectional estimates at subprovincial levels. Therefore, the Ontario part of the NPHS 1996/97 is also referred as OHS 1996/97. The total sample size for the Ontario health micro-data file in the NPHS 1996/97 cycle is 39,010 . The sample size is 7,102 for the senior population, 31,908 for the nonsenior population.

For Ontario, data collection ran from October 1996 to August 1997, completely after the reform of provincial drug plans in July 1996. Before July 15 1996, Ontario provided first dollar coverage without any co-payment to its senior citizens. After that, income and household size based deductible and dispensing fee were imposed. Similarly, a \$2 dispensing fee was introduced after July 151996 for the non-senior social assistance recipients eligible for the provincial drug plan.

\section{CCHS 2000-2001}

The CCHS 2000/01 is the first cycle of the Canadian Community Health Survey, a large sample, general population health survey. Information was collected between 
September 2000 and November 2001, for 136 health regions, covering all provinces and territories. The CCHS (Cycle 1.1) collects responses from persons aged 12 or older, living in private occupied dwellings. Individuals living on Indian Reserves and on Crown Lands, institutional residents, full-time members of the Canadian Armed Forces, and residents of certain remote regions are excluded.

The CCHS 2000/01 asked each subject 21 questions as to whether this individual has taken a particular kind of drug in the past month. The questions are the same as in the NPHS 1996/97. A derived variable on "number of different drugs taken in the past month" can be constructed based on those questions, and is the measurement of drug utilization in this analysis. One limitation is that the questions on drug use are optional in the CCHS 2000/01. Only regions with a need for data or interest in this topic selected it in the CCHS. $100 \%$ of the respondents in only 29 public health regions (out of 37) answered those questions. The other 8 public health regions did not select this topic. ${ }^{5}$ Therefore, the observations in those 8 public health regions are excluded from this analysis. The number of excluded observations is $20.7 \%$ of total observations, but it only represents $16.1 \%$ of Ontario population. The comparison on descriptive statistics of some key characteristics related to health care utilization between the included observations and excluded observations is presented in Table 1 . The two sets of numbers are very close, which suggests no bias in terms of observed characteristics. In addition, individual respondents played no role in the decision of whether or not to answer these questions, so there is no individual-level selection process at work. Hence, although the missing data are unfortunate, little reason to believe it introduced serious selection bias. The CCHS 2000/01 also contains measures of health status, socioeconomic status, household and demographic 
information, income, etc. A further problem is that the information on additional medical insurance is not collected in CCHS 2000/01.

The total sample size for the analysis based on the CCHS is 31,133. The sample size for the senior population is 25,108 , and for the non-senior population is 6,025 .

\subsection{Variables}

In this analysis, I adopt the methods developed by the ECUITY group in recent years (Van Doorslaer et al. 2002; Van Doorslaer et al. 2004; Van Doorslaer et al. 2000; Van Doorslaer et al. 1992; Wagstaff and Van Doorslaer 2000a).This method has been applied to many countries internationally, and to EU countries in particular on the issues of equity in health care utilization. It has been applied at the national level in Canada with respect to hospital and MD services. However, it has never been applied to equity in drug utilization anywhere. The approach involves four basic steps at each time point for each population group:

1) Calculate the concentration index (CI) to measure the inequality in observed drug use.

2) Use a two-part model to indirectly need-standardize the drug use.

3) Calculate the horizontal inequity index (HI) to measure the inequity in drug use.

4) Decompose the inequality into its causes.

The details of the method are discussed in the next sub-section. The variables used in the two-part model are discussed below. 


\section{$\underline{\text { Dependent Variable }}$}

The 1990 OHS asks each subject "How many different numbers of prescription drugs have you taken in the last 4 weeks?”; NPHS health micro-data file and CCHS contain 21 identical questions about whether the respondent has taken a particular kind of drug in the past month. The information is used to create the two dependent variables. The first is a dichotomous variable indicating whether a person consumed at least one drug in the last month. The second is the number of drugs used conditional on positive use.

There are two limitations to these measures of utilization. First, the number of different drugs taken in the past month is a crude measurement of drug utilization. It is related only to the crude measurement of quantity rather than the quality of drug use. If data allowed, a more accurate measurement of drug utilization would give better estimation and understanding of this issue. This is a very common issue in most existing studies on the issue of equity in health care utilization. The commonly used dependent variables are number of physician visits, number of dentist visits, and number of nights of hospital stay, etc. Secondly, utilization in the NPHS and CCHS data include both prescribed and nonprescribed drugs, while the OHS includes only prescribed drugs. This may lead to inconsistency of the results.

\section{$\underline{\text { Independent Variables }}$}

Table 2 lists the independent variables included in the two-part model and briefly describes the rationale for their inclusion. The independent variables can be categorized into three groups: demographic variables, health status variables and social-economic variables. The demographic variables include indicators of age, sex and immigrant status. 
Usually, there are strong relations between health care utilization and age and sex. Many studies (e.g., Deri 2005) have found lower rates of health care utilization among immigrants, therefore, an immigrant variable is included in the model. The health status variables include self-assessed health status, number of chronic conditions and illness and injury in the past two weeks. The social-economic variables include income per household member, education level, working status, and additional medical insurance. Income per household member is a critical variable in this analysis; it is created as follows. The OHS 1990 and NPHS 1996/97 contain categorical information on total household income (0-\$5000, \$5000-\$9999, \$10000-\$14999, \$15000-\$19999, \$20000-24999, \$25000-\$29999, \$30000\$39999, \$40000-\$49999, \$50000-\$59999, \$60000-\$79999, \$80000+). The CCHS 2000/01 contains information on best estimate of total household income. All the datasets also contain information on number of individuals in the household. Income per household is defined as the mid point of the total household income in each category divided by the number of household members in that household. Several variables may capture multiple influences on drug utilization, such as education and working status, which are also discussed in Table 2. The main purpose of the regression model is prediction rather than the estimation of a causal relationship. Therefore, it is not a structural model.

The descriptive statistics of the variables are presented in Table 3 and Table 4. The means of most independent variables are relatively constant over time; one exception is the income per household member variable, which increased over time. For the non-seniors, there are significant increases of the two dependent variables. The average number of drugs used increased from 1.023 to 1.836 , and the probability of drug use increased from 0.53 to 
0.805 from 1990 to 2000/01. For the senior population, the number of drugs used and the probability of drug use increased slightly over time.

\subsection{Method}

Step 1-Concentration Index for Observed Drug Utilization

The concentration index quantifies the degree of inequality in a specific health variable - in this case number of drugs consumed - across the income distribution. It is defined with the reference to the concentration curve. The concentration curve graphs on the $x$-axis the cumulative percentage of the population ranked by income and on the $y$-axis the cumulative percentage of drug consumption.

If there is no income-related inequality, the concentration curve is the $45^{0}$ line. If drug consumption is more concentrated among the poor, the concentration curve lies above the line of equality. If drug consumption is more concentrated among the rich, the concentration curve lies below the line of equality. The concentration index is defined as twice the area between the concentration curve and the line of equality (the $45^{\circ}$ line). If the concentration curve is above the $45^{\circ}$ line, indicating that drug consumption is more concentrated among the poor, the concentration index takes on a negative value. If the concentration curve is below the $45^{0}$ line, indicating that drug consumption is more concentrated among the rich, the concentration index takes on a positive value. The concentration index ranges from -1 to $1,-1$ means that the poorest person gets all the drugs consumed while 1 means that the richest person gets all the drugs consumed, and 0 means that drug consumption is the same for every income level. 
The concentration index is calculated by the following formula:

$$
C=\frac{2}{n \mu} \sum_{i=1}^{n} y_{i} R_{i}-1
$$

where $y_{i}$ is the drug consumption for individual $i, R_{i}$ is the rank of income for that individual, $\mu$ is the mean of drug consumption, and $n$ is the number of individuals. Both the concentration index and its variance can easily be computed using conventional statistical software packages. With the standard error, we can test the statistical significance of the concentration index and calculate its confidence interval.

The concentration index simply measures whether utilization is equal across the income groups. The goal of a health care system is equity rather than equality. To assess equity, we must assess the extent to which utilization is driven by need.

\section{Step 2-Indirect Need-standardization of Drug Utilization}

At the second step, I use a two-part model to indirectly need-standardize the drug utilization. The goal of a health care system is equity rather than equality. A key principle of equity for health care systems is allocation according to need. Under this principle, horizontal equity requires that persons in equal need of treatment should receive the same amount of treatment. Because the concentration index measures only the income-related inequality in observed drug utilization, an analysis of equity in drug utilization requires that we adjust for underlying need.

To adjust for need, I use the indirect need-standardization approach proposed by Wagstaff and Van Doorsaler (2000). The measure of drug utilization used in this analysis is the number of drugs used in the past month. The need-adjusted drug utilization can be 
predicted by a two-part model. Jones (2000) provides an overview of the econometric methods that have been applied to this kind of count data. For the health data, it is common to have a large proportion of zero observation, and "overdispersion”. Overdispersion means that the variance of the distribution exceeds the mean. The two-part model accommodates the high proportion of zeros. Under the two-part model in this situation, the first part is a logit regression, and the second part is a Negative binomial regression, which deals with the "overdispersion". The dependent variable in the first part of the two-part model is a dichotomous variable indicating whether a person consumed at least one drug in the last month. The dependent variable in the second part of the two-part model is the number of drugs used conditional on positive use. With the two-part model, not only we could measure the equity in the number of drugs used, but also we could measure the equity in the probability of drug use. Moreover, several studies (Grootendorst 1995; Jones 2000; Van Doorslaer et al. 2000) show that the two-part model is the best choice when the dependent variable is a quantitative measure of health care utilization. Therefore, I adopt the two-part model approach with appropriate modelling of the count data.

To measure equity, we need to create a measure in which utilization does not reflect the influence of non-need factors; it reflects what utilization would be like if only needs drove utilization. Therefore, the need-standardization requires that each variable be classified as need-related or non-need-related. In this analysis, the following variables are classified as need factors: self-assessed health status, age, number of chronic diseases and illness/injury in the past two weeks; and the other variables are classified as non-need factors: income, education level, immigrant status, additional insurance status, working status. There is no unanimous agreement about what factors should be considered as need 
factors. Some researchers argue that some factors, such as education and working status, should also be considered as need factors. In this case, I simply take the demographic and morbidity factors as need factors, because these are much less controversial and are most commonly defined as need factors in the equity studies of health care utilization.

After the estimation of each part, I fix the non-need factors at the sample means, and then predict the need-standardized probability and need-standardized number of drugs used conditional on positive use based on the need factors. By doing so, we assume the population average relationship between need and treatment as the norm of equity. The need-standardized expected total number of drug use is equal to the product of needstandardized probability and need-standardized conditional number.

\section{$\underline{\text { Step 3-Horizontal Inequity Index }}$}

In the third step, I calculate the horizontal inequity index (HI) for the probability of any drug use, conditional number of drugs used and total number of drugs used.

The horizontal inequity index is equivalent to the concentration index for $y^{I S}$ (Van Doorslaer et al. 2000), where

$$
y_{i}^{I S}=y_{i}-\hat{y}_{i}+y^{m}
$$

where $y_{i}$ is the measure of actual drug utilization in the past month, $\hat{y}_{i}$ is the need-adjusted measure of drug utilization, and $y^{m}$ is the sample mean of the measure of drug utilization in the past month. 


\section{Step 4-Decomposition of Inequality}

At the last step, I decompose the inequality in observed utilization into its causes. I adopt the decomposition method proposed in Wagstaff et al. (2003). In order to use this method, the number of drugs used has to be expressed by a linear equation of a set of variables that determine drug utilization. In other words, the decomposition has to be based on an OLS regression. Van Doorsaler et al. (2004) argue that in most cases, the concentration index based on OLS predicted values is close to the true concentration index, even if the dependent variable is a count measure. In my case, the concentration index based on OLS predicted values is also close to the true concentration index. Therefore, I follow the OLS approach. However, because of the nature of count data, the OLS based decomposition of inequality is an approximation only.

In an OLS regression, the number of drugs used can be expressed as

$$
y_{i}=\alpha+\sum_{k} \beta_{k} x_{k i}+\varepsilon_{i}
$$

where $x_{k}$ is a set of $k$ determinants of $y$. The concentration index is

$$
C=\frac{2}{n \mu} \sum_{i=1}^{n} y_{i} R_{i}-1
$$

Substitute equation (3) into the above equation, it can be rearranged as

$$
C=\sum_{k}\left(\frac{\beta_{k} x_{k}}{\mu}\right) C_{k}+\frac{G C_{\varepsilon}}{\mu}
$$

Where $\frac{\beta_{k} x_{k}}{\mu}$ is the elasticity of drug use with respect to determinant $k$; $C_{k}$ is the CI for variable $\mathrm{k}$, and $\frac{G C_{\varepsilon}}{\mu}$ is an error term. The estimated inequality in drug use can be 
expressed as a weighted sum of the inequality in each of its determinants; the weights are the drug use elasticities of the determinants. Based on the OLS regression, I decompose the concentration index for each population group.

\section{Results}

\section{Step 1: Concentration indices for observed drug use}

Figure 1 and Figure 2 present the average number of drugs used and the average number of drugs used for those who have consumed drugs by income quartile. The bar graphs can give us a more intuitive impression on the inequality in drug use before I report the concentration indices. Generally speaking, people in the lower income quartiles use more drugs than people in the higher income quartiles. ${ }^{6}$ Seniors use more drugs than nonseniors. And there is a trend of increase in drug utilization over time.

The concentration indices measuring the income-related inequality on observed drug use are reported in Table 5. The distribution is pro-poor for the senior population at all three time points, although not significantly different from zero in 1996/97. For the nonsenior population, the distribution is pro-poor in 1990 and pro-rich in 1996/97 and 2000/01. At all time points, the concentration indices of the senior population are more negative or, when positive, smaller (more pro-poor) than those for the non-senior population. From 1990 to $1996 / 97$, there is an increase of the concentration index for both the senior and nonsenior population. The distribution is less pro-poor over time. This change may result from the imposition of deductibles and co-payments of ODB for seniors and from a rapid increase of drug utilization for non-seniors. During this period, for the non-senior population, the average number of drugs used increased from 1.02 to 1.66 , and the 
probability of drug use increased from 0.53 to 0.78 . This increase reflects the changes in health technology, whereby more conditions are being treated outside hospital settings. The increased drug utilization might be unbalanced in favour of the rich. From 1996/97 to 2000/01, the concentration index for the senior population slightly decreases (more propoor), while there is no significant change for the non-senior population. During this period, there is no drug policy change for seniors, and the introduction of the Trillium Drug Program and the Special Drug Program may mitigate the worsening of the income-related inequality among the non-senior population. From 1996 to 2001, the number of TDP applications increased from 18,172 to 59,599 , and the total SDP cost increased from $\$ 82.6$ million to $\$ 107.3$ million. The aims of these two programs are to help those most in need and who have greatest financial constraints. Given the income-related inequality in drug utilization is relatively small, the TDP and SDP may have significant influence on the distribution of drug utilization across income groups.

\section{Step 2-Indirect Need-standardization of Drug Utilization}

The goal of most health care systems is equity rather than equality. In order to measure horizontal inequity, observed drug utilization must be indirectly need-standardized, after which we can compute the horizontal inequity index.

The first part of the two-part model is a logit model on the probability of drug use. The second part of the two-part model is a negative binomial model conditional on positive drug use. In view of space considerations, the results of the two-part model are not reported here. ${ }^{7}$ The general patterns are very similar for both parts. Generally speaking, at all three time points, for both the senior and non-senior population, there is a strong relationship 
between drug utilization and need factors (number of chronic diseases, illness/injury in the past two weeks, self-assessed health status, sex, age). Drug use is increasing in the number of chronic diseases and worse self-assessed health status. The link between drug use and non-need factors (education, immigration status, additional drug insurance, working status and income) is much weaker. However, compared to the senior population, the link between drug use and non-need factors is more salient for non-seniors. The role of education, income, and immigrant in drug use are less significant for seniors. For both seniors and non-seniors, at the later two time points, the magnitude of the link between drug use and need factors is weaker than that in 1990, and the link between drug use and non-need factors is stronger.

After the estimation, I fix the non-need factors at the sample means, and then predict the need-standardized probability of drug use, number of drugs used conditional on positive use, and total number of drugs used based on the need factors.

\section{Step 3-Horizontal Inequity Index}

In the third step, I calculate the horizontal inequity index (HI) for the probability of drug use, drugs used conditional on positive use, and total number of drugs used. The results are presented in Table 6.

There are no evidences of inequity in most aspects of drug use for both seniors and non-seniors in 1990. The only exception is that the probability of drug use for non-seniors is distributed slightly pro-rich. However, this pro-rich distribution for the probability of drug use is offset by the pro-poor distribution for drugs used conditional on positive use; therefore, there is no measured income-related inequity in the total number of drugs used 
even for non-seniors in 1990. There is evidence of income-related inequity for almost all the aspects of drug use for both seniors and non-seniors in 1996/97 and 2000/01. However, there are no significant differences in the level of inequity between the later two time points. The worsening of equity may result partially from the same reasons that lead to the worsening of inequality. I will discuss this in more details at next step.

At all the three time points, on all aspects of drug use, the equity performance for seniors is better than that of non-seniors. The HI indices for seniors are more negative or, when positive, smaller (more pro-poor) than that for non-seniors. Universal drug coverage for the senior population might play an important role in drug utilization.

\section{Step 4-Decomposition of inequality}

At each time point, for each population group, I decompose the unadjusted inequality (the concentration index) into the separate contributions of the various determinants to the total inequality. The summarization of decomposition results are presented in Table 7 and Figure 3.

At all three time points, the overall concentration indices for senior population are more negative or smaller than that for non-senior population. There is a more pro-poor distribution in drug use among seniors. The decompositions show that the most important source of the more pro-poor distribution among seniors is that more seniors suffer from poor health, and poor health among the seniors is concentrated among the poor. Compared to non-seniors, the need factors, such as higher number of chronic conditions, worse selfassessed health statuses, and illness/injury in the past two weeks, are more concentrated among the poor. Therefore, the concentration indices of these factors for seniors are more 
negative. Moreover, there is positive relationship between drug use and the need factors. Therefore, for seniors, the need factors make larger negative contributions to the total CI's. Among non-seniors, people with relatively higher age usually have worse health status and higher income; therefore, the need factors are less concentrated among the poor, and thus make less negative contributions to the total CI's. Part of the gap in the CI's between seniors and non-seniors results from the variables of education, immigration status and additional drug insurance. Higher education levels and having additional medical insurance are concentrated more among the rich in both the senior and non-senior population. At the same time, the positive relationships between drug use and these two variables for nonseniors are stronger than those for seniors. Therefore, these two variables make positive contributions to the gap of inequality in drug use between seniors and non-seniors. Immigrants use fewer health care services presumably because of language barriers and lack of information about the Canadian health care system, or some other cultural reasons. However, immigration status has a different influence on drug use between senior and nonsenior populations. Generally speaking, the negative relationship between immigration status and drug utilization is more significant for non-seniors. Moreover, for both seniors and non-seniors, immigrants on average have less income, which implies the concentration indices for immigration status are negative. Therefore, immigration status makes a positive contribution to the gap of inequality in drug use between seniors and non-seniors. Generally speaking, without universal coverage, the drug utilization of non-seniors is more influenced by non-need factors.

For both seniors and non-seniors, the most important source for the worsening of inequality in drug use over time comes from the income variable. In 1990, there is a 
negative but statistically insignificant relationship between drug use and income. In 1996/97 and 2000/01, the relationships between drug use and income become positive and statistically significant, and leads to an increase of both inequality and inequity in drug use. This change might be related to the introduction of deductibles and co-payments of ODB for seniors, and the rapid increase in drug utilization for non-seniors during that period.

However, because we define equity in drug use in this study as drug use according to need, and poor seniors are more in need, therefore, the gap of inequity in drug use (HI) ${ }^{8}$ between seniors and non-seniors is not as large as the gap of inequality in drug use (CI) between seniors and non-seniors. The horizontal inequity index measures only the inequality in drug use that results from non-need factors. The gap in the HI's between seniors and non-seniors is smaller than the gap in the CI's.

\section{Conclusion}

This study analyzes the equality and equity in pharmaceutical utilization in Ontario, an issue which has not previously been examined. In 1990, I find no evidence for pro-rich inequality and inequity in drug utilization in Ontario for both senior and non-senior populations. In 1996/97 and 2000/01, I find evidence for pro-rich inequality and inequity for both population groups. At all three time points, the equality and equity performance in drug utilization for the senior population dominates that of the non-senior population. Universal drug coverage for the senior population might play a role in drug utilization. From 1990 to 1996/97, there is a worsening in equality and equity performance for both senior and non-senior populations, so that the distribution is less pro-poor over time. This result might be partly related to the introduction of deductibles and co-payments for ODB 
for seniors and to the rapid increase of drug utilization during this period. From 1996/97 to 2000/01, the equality and equity performance for the senior population slightly decreased, while there is no significant change for the non-senior population. The introduction of the Trillium Drug Program and the Special Drug Program might mitigate the worsening of income-related inequality and inequity among the non-senior population.

Decomposing the inequality into its causes reveals that poor seniors are more in need of drug utilization than poor non-seniors, resulting in more pro-poor distribution of drug utilization among seniors. The gap in equity performance between seniors and nonseniors is not as large as the gap in equality. The gap in equity performance between seniors and non-seniors mainly results from the variables of education, immigration status and additional drug insurance. Without universal coverage, these variables have greater influence on drug utilization among non-seniors. For both seniors and non-seniors, the most important cause of worsening equality and equity in drug use over time comes from the income variable. This relationship between drug use and income becomes positive and statistically significant over time.

These findings may be confounded by other system changes in the health care sector during the study period. The major changes in the physician sector during 1990's would be the introduction and then removal of global physician expenditure caps. The other major change would have been hospital restructuring in the late 1990's. These system changes may have influence on drug utilization. However, the impact from these changes on the distribution of drug use should be much smaller than the impact on the overall drug use. 
The most important policy implication to be derived from this study is that equity performance in drug utilization is closely related to drug coverage policy. Expansion of special public drug programs for people highly in need (for example, TDP and SDP), or introducing programs for under-utilizing groups such as immigrants (for example, programs to reduce language barriers) would improve equity in drug utilization.

\section{Notes}

I would like to thank Jerry Hurley, Tom Crossley, and an anonymous referee for helpful comments. I also acknowledge the data support by Statistics Canada RDC at McMaster and UWO.

${ }^{1}$ First-dollar coverage refers to the health insurance plan without deductibles and copayments.

${ }^{2}$ Values are converted in 2004 constant dollars.

${ }^{3}$ Approximately 1.9\% out of total drug expenditure in Ontario in 1996 and 1.7\% in 2000.

${ }^{4}$ It's difficult to estimate the size of this group of people. According to Social Development Canada (2005), in each year, 5\% to 8\% Ontarians received social assistance from 1999 to 2004. Among them, a significant proportion is children and seniors.

5 The eight excluded PHU's are: Haliburton-Kawartha-Pine Ridge PHU, Hastings and Prince Edward PHU, Brant PHU, Renfrew PHU, KFLA PHU, Ottawa-Carleton PHU, Eastern Ontario PHU and Leeds-Grenville-Lanark PHU. 
${ }^{6}$ These seemingly "pro-poor" results are not yet adjusted for need and if the poor have greater need, it may nonetheless be the case that the utilization of drugs is not equitable with the poor possibly receiving less drugs than would be equitable based on need.

${ }^{7}$ Results of step 2 are available upon request.

${ }^{8}$ By definition, HI index is equal to the sum of contributions of non-need factors to the total inequality.

\section{References}

Alan, S., T. Crossley, P. Grootendorst, and M. Veall. 2005. "Distributional Effects of General Population Prescription Drug Programs in Canada.” Canadian Journal of Economics 38:128-148.

Alan, S., T. Crossley, P. Grootendorst, and M. Veall. 2002. “The Effects of Drug Subsidies on Out-of-pocket Prescription Drug Expenditures by Seniors: Regional Evidence from Canada.” Journal of Health Economics 21:87-108.

Alter, D., D. Naylor, P. Austin, and J. Tu. 1999. "Effects of Socioeconomic Status on Access to Invasive Cardiac Procedures and on Mortality after Acute Myocardial Infarction.” New England Journal of Medicine 341: 1359-1367.

Canadian Institute for Health Information. 2005a. Drug Expenditure in Canada, 1985 to 2004. Ottawa: CIHI.

Canadian Institute for Health Information. 2005b. National Health Expenditure Trends, 1975 to 2004. Ottawa: CIHI.

Deri, C. 2005. "Social Networks and Health Service Utilization." Journal of Health Economics 24:1076-1107.

Eyles, J., S. Birch, and K. Newbold. 1995. "Delivering the Goods? Access to Family Physician Services in Canada: A Comparison of 1985 and 1991.” Journal of Health and Social Behaviour 36:322-332.

Fraser Group and Tristat Resources. 2002. Drug Expense Coverage in the Canadian Population: Protection from Severe Drug expenses. Toronto: Fraser Group and Tristat Resources. 
Grootendorst, P. 1995. “A Comparison of Alternative Models of Prescription Drug Utilization.” Health Economics 4: 183-198.

Grootendorst, P. 2002. "Beneficiary Cost Sharing under Canadian Provincial Prescription Drug Benefit Programs: History and Assessment.” The Canadian Journal of Clinical Pharmacology 9:1-21.

Jones, A. 2000. "Health Econometrics," in Handbook of Health Economics, ed. A. Culyer and J. Newhouse. Amsterdam: North Holland.

Newbold, K., J. Eyles, and S. Birch. 1995. "Equity in Health Care: Methodological Contributions to the Analysis of Hospital Utilization within Canada.” Social Science \& Medicine 40: 1181-1192.

Ontario Ministry of Health and Long Term Care. 2005. 2004/05 Report Card for the Ontario Drug Benefit Program. Toronto: MOHLTC.

Social Development Canada. 2005. Social Assistance Statistical Report: 2004. Ottawa: Social Development Canada.

Van Doorslaer E., X. Koolman, and F. Puffer. 2002. "Equity in the Use of Physician Visits in OECD Countries: Has Equal Treatment for Equal Need Been Achieved?” In Measuring Up: Improving Health Systems Performance in OECD Countries, 225-248. Paris: OECD.

Van Doorslaer E., C. Masseria, and the OECD Health Equity Research Group Members. 2004. "Income-related Inequality in the Use of Medical Care in 21 OECD Countries." OECD Health Working Papers No. 14.

Van Doorslaer E., A. Wagstaff, and et al. 2000. "Equity in the Delivery of Health Care in Europe and the U.S.” Journal of Health Economics: 553-583.

Van Doorslaer E., A.Wagstaff, S. Calonge, and et al. 1992. "Equity in the Delivery of Health Care: Some International Comparisons. Journal of Health Economics 11: 389411.

Wagstaff A. and E. Van Doorslaer. 2000. "Equity in Health Care Financing and Delivery," in Handbook of Health Economics, ed. A. Culyer and J. Newhouse. Amsterdam: North Holland.

Wagstaff A. and E. Van Doorslaer. 2000. "Measuring and Testing for Inequity in the Delivery of Health Care.” Journal of Human Resource 35:716-733.

Wagstaff, A., E. Van Doorslaer, and N. Watanabe. 2003. “On Decomposing the Causes of Health Sector Inequalities with an Application to Malnutrition Inequalities in Vietnam.” Journal of Econometrics 112 (1): 207-223. 


\section{Tables}

Table-1, Comparison of descriptive statistics between included and excluded PHU's, CCHS 2000/01

\begin{tabular}{l|rr|rr}
\hline & Excluded PHU's & Included PHU's \\
\cline { 2 - 5 } & Mean & $\begin{array}{r}\text { Std. } \\
\text { dev. }\end{array}$ & Mean & $\begin{array}{r}\text { Std. } \\
\text { dev. }\end{array}$ \\
\hline Household income & 60339 & 31452 & 61510 & 31166 \\
Education- less than high school & 0.270 & 0.444 & 0.269 & 0.444 \\
Education- high school & 0.197 & 0.397 & 0.209 & 0.406 \\
Education- some post secondary & 0.073 & 0.260 & 0.077 & 0.267 \\
Education- post secondary graduation & 0.451 & 0.498 & 0.438 & 0.496 \\
Female & 0.511 & 0.500 & 0.509 & 0.500 \\
Age 12-14 & 0.048 & 0.213 & 0.044 & 0.205 \\
Age 15-19 & 0.080 & 0.271 & 0.081 & 0.273 \\
Age 20-24 & 0.077 & 0.266 & 0.081 & 0.273 \\
Age 25-29 & 0.076 & 0.264 & 0.080 & 0.271 \\
Age 30-34 & 0.077 & 0.267 & 0.088 & 0.283 \\
Age 35-39 & 0.100 & 0.300 & 0.110 & 0.313 \\
Age 40-44 & 0.104 & 0.305 & 0.103 & 0.303 \\
Age 45-49 & 0.084 & 0.278 & 0.093 & 0.290 \\
Age 50-54 & 0.089 & 0.285 & 0.077 & 0.267 \\
Age 55-59 & 0.065 & 0.247 & 0.057 & 0.233 \\
Age 60-64 & 0.047 & 0.213 & 0.046 & 0.210 \\
Age 65-69 & 0.051 & 0.220 & 0.043 & 0.204 \\
Age 70-74 & 0.039 & 0.194 & 0.039 & 0.195 \\
Age 75-79 & 0.033 & 0.177 & 0.030 & 0.170 \\
Age 80+ & 0.030 & 0.171 & 0.027 & 0.163 \\
Self-assessed health- excellent & 0.254 & 0.435 & 0.267 & 0.442 \\
Self-assessed health-very good & 0.373 & 0.484 & 0.365 & 0.481 \\
Self-assessed health-good & 0.250 & 0.433 & 0.246 & 0.431 \\
Self-assessed health-fair & 0.088 & 0.283 & 0.086 & 0.280 \\
Self-assessed health-poor & 0.034 & 0.181 & 0.036 & 0.186 \\
Number of family doctor visits in past & & & & \\
year & 3.407 & 4.778 & 3.402 & 4.602 \\
\hline
\end{tabular}


Table-2, Independent Variables: Description and Rationale for Inclusion

\begin{tabular}{|c|c|c|}
\hline Variable & Description and Rationale & $\begin{array}{l}\text { Need } \\
\text { Status }\end{array}$ \\
\hline \multicolumn{3}{|c|}{ Demographics } \\
\hline Age & $\begin{array}{l}\text { Age of the respondent at the time of interview. Age is defined by a series of } 15 \text { categorical variables. } \\
\text { The reference category is age } 12-14 \text {. Age is associated with chronic health decline and need for drugs. } \\
\text { The use of age-specific dummy variable allows maximum flexibility in the age-utilization relationship. }\end{array}$ & $\mathrm{Y}$ \\
\hline Female & $\begin{array}{l}\text { Male and female have different attitudes and needs for health care services. Sex is indicated by a } \\
\text { dummy variable, at which female is } 1 \text { and male is } 0 .\end{array}$ & $\mathrm{Y}$ \\
\hline Immigrant & $\begin{array}{l}\text { Indicator of whether the respondent is an immigrant. Immigrant is defined in all the three surveys as } \\
\text { not born in Canada. Immigrants may experience barriers to drug utilization because of language } \\
\text { barriers and lack of information about the Canadian health care system. }\end{array}$ & $\mathrm{N}$ \\
\hline \multicolumn{3}{|c|}{ Health Status } \\
\hline $\begin{array}{l}\text { Self- } \\
\text { assessed } \\
\text { health } \\
\text { status }\end{array}$ & $\begin{array}{l}\text { Respondent's self-assessed health status, defined by a series of } 5 \text { categorical variables (Excellent, } \\
\text { Very Good, Good, Fair, And Poor). The reference category is excellent. Self-assessed health status is } \\
\text { a well-validated general health measure, which is strongly associated with drug utilization. }\end{array}$ & $\mathrm{Y}$ \\
\hline Illness/injury & $\begin{array}{l}\text { Indicator of whether the respondent has illness or injury (self-reported) in the past two weeks. } \\
\text { Illness/injury refers to conditions that related to stay in the bed or cutting down on activities, which may } \\
\text { positively relate to drug utilization. }\end{array}$ & $\mathrm{Y}$ \\
\hline $\begin{array}{l}\text { Chronic } \\
\text { conditions }\end{array}$ & $\begin{array}{l}\text { Respondent's self-reported number of chronic conditions. Chronic conditions are strongly associated } \\
\text { with drug utilization. }\end{array}$ & $\mathrm{Y}$ \\
\hline \multicolumn{3}{|c|}{ Socio-economic Status } \\
\hline Income & $\begin{array}{l}\text { Income per household member, in thousands. Income may be positively related to the drug utilization. } \\
\text { Even for the individuals who have drug insurance coverage, most of them are required to pay a } \\
\text { deductible and/or co-payment for the prescription drugs. }\end{array}$ & $\mathrm{N}$ \\
\hline Education & The highest level of education attained by the respondent. Education is defined through a series of & $\mathrm{N}$ \\
\hline
\end{tabular}




\begin{tabular}{|l|l|l|l|}
\hline & $\begin{array}{l}\text { dummy variables (less than high school, high school, some post-secondary, with a degree). Education } \\
\text { has two opposite potential influences on drug utilization: 1) higher education levels are associated with } \\
\text { better health which may have negative influence on drug use. 2) higher education levels are } \\
\text { associated with positive attitude to health care which may have a positive influence on drug use. }\end{array}$ & \\
\hline $\begin{array}{l}\text { Working } \\
\text { Status }\end{array}$ & $\begin{array}{l}\text { Indicator of whether the respondent has held a job (either full time or part time) in the past year. Labour } \\
\text { force participation has two opposite potential influences on drug utilization: 1) higher time cost and } \\
\text { better health associated with labour force participation may have negative influence on drug use. 2) } \\
\text { higher income and better private drug coverage associated with labour force participation may have a } \\
\text { positive influence on drug use. }\end{array}$ & $\mathrm{N}$ \\
\hline Insurance & $\begin{array}{l}\text { Indicator of whether the respondent has insurance that covers all or part of the cost of prescription } \\
\text { medications (Include any private, government or employer-paid plans). It may positively relate to drug } \\
\text { utilization. This variable is missing in CCHS 2000/01. }\end{array}$ & $\mathrm{N}$ \\
\hline
\end{tabular}


Table-3, Descriptive statistics, Non-senior Population

\begin{tabular}{|c|c|c|c|c|c|c|}
\hline & \multicolumn{6}{|c|}{ Non-senior Population } \\
\hline & \multicolumn{2}{|c|}{1990 OHS } & \multicolumn{2}{|c|}{ 1996/97 NPHS } & \multicolumn{2}{|c|}{$2000 / 01 \mathrm{CCHS}$} \\
\hline & mean & $\begin{array}{l}\text { std } \\
\text { dev. }\end{array}$ & mean & $\begin{array}{l}\text { std } \\
\text { dev. }\end{array}$ & mean & $\begin{array}{l}\text { std } \\
\text { dev. }\end{array}$ \\
\hline Number of drugs used & 1.023 & 1.825 & 1.660 & 1.528 & 1.836 & 1.630 \\
\hline Probability of any drug use & 0.530 & 0.757 & 0.781 & 0.414 & 0.805 & 0.397 \\
\hline Income & 16.770 & 10.721 & 20.202 & 14.536 & 24.4822 & 20.532 \\
\hline Female & 0.505 & 0.500 & 0.521 & 0.500 & 0.501 & 0.500 \\
\hline Age $15-19$ & 0.106 & 0.307 & 0.069 & 0.254 & 0.094 & 0.292 \\
\hline Age $20-24$ & 0.092 & 0.290 & 0.086 & 0.280 & 0.094 & 0.292 \\
\hline Age $25-29$ & 0.114 & 0.318 & 0.106 & 0.307 & 0.092 & 0.290 \\
\hline Age $30-34$ & 0.122 & 0.328 & 0.134 & 0.340 & 0.102 & 0.303 \\
\hline Age $35-39$ & 0.118 & 0.323 & 0.137 & 0.344 & 0.128 & 0.334 \\
\hline Age $40-44$ & 0.108 & 0.310 & 0.109 & 0.312 & 0.119 & 0.324 \\
\hline Age $45-49$ & 0.087 & 0.282 & 0.093 & 0.290 & 0.108 & 0.310 \\
\hline Age $50-54$ & 0.072 & 0.259 & 0.085 & 0.279 & 0.090 & 0.286 \\
\hline Age 55-59 & 0.071 & 0.257 & 0.072 & 0.258 & 0.067 & 0.250 \\
\hline Age $60-64$ & 0.066 & 0.249 & 0.069 & 0.253 & 0.054 & 0.226 \\
\hline With 1 chronic condition & 0.308 & 0.462 & 0.270 & 0.444 & 0.276 & 0.447 \\
\hline With 2 chronic conditions & 0.176 & 0.381 & 0.145 & 0.352 & 0.161 & 0.368 \\
\hline With 3 chronic conditions & 0.088 & 0.283 & 0.073 & 0.261 & 0.082 & 0.275 \\
\hline With $4+$ chronic cc & 0.075 & 0.263 & 0.073 & 0.260 & 0.081 & 0.273 \\
\hline Illness/injury in past 2 weeks & 0.124 & 0.330 & 0.119 & 0.324 & 0.094 & 0.292 \\
\hline Self-assessed he & 0.303 & 0.460 & 0.403 & 0.491 & 0.385 & 0.487 \\
\hline Self-assessed health-good & 0.214 & 0.410 & 0.238 & 0.426 & 0.235 & 0.424 \\
\hline Self-asse & 0.053 & 0.225 & 0.067 & 0.249 & 0.064 & 0.246 \\
\hline Self-assessed health-poor & 0.013 & 0.115 & 0.024 & 0.153 & 0.026 & 0.158 \\
\hline Education-high school & 0.242 & 0.429 & 0.181 & 0.385 & 0.210 & 0.408 \\
\hline Education-some post secondary & 0.237 & 0.425 & 0.403 & 0.491 & 0.349 & 0.477 \\
\hline Education-degree & 0.109 & 0.312 & 0.167 & 0.373 & 0.193 & 0.394 \\
\hline Immigrant & 0.190 & 0.392 & 0.189 & 0.392 & 0.307 & 0.461 \\
\hline Working & 0.634 & 0.482 & 0.649 & 0.477 & 0.745 & 0.436 \\
\hline Additional insurance & 0.717 & 0.451 & 0.680 & 0.466 & --- & --- \\
\hline
\end{tabular}


Table-4, Descriptive statistics, senior Population

\begin{tabular}{|c|c|c|c|c|c|c|}
\hline & \multicolumn{6}{|c|}{ Senior Population } \\
\hline & \multicolumn{2}{|c|}{$1990 \mathrm{OHS}$} & \multicolumn{2}{|c|}{$1996 / 97$ NPHS } & \multicolumn{2}{|c|}{ 2000/01 CCHS } \\
\hline & mean & $\begin{array}{l}\text { std } \\
\text { dev. }\end{array}$ & mean & $\begin{array}{l}\text { std } \\
\text { dev. }\end{array}$ & mean & $\begin{array}{l}\text { std } \\
\text { dev. }\end{array}$ \\
\hline Number of drugs used & 2.585 & 2.735 & 2.310 & 1.797 & 2.983 & 2.036 \\
\hline Probability of any drug use & 0.868 & 0.810 & 0.873 & 0.333 & 0.922 & 0.268 \\
\hline Income & 14.935 & 10.387 & 18.874 & 11.879 & 21.950 & 18.008 \\
\hline Female & 0.561 & 0.496 & 0.598 & 0.490 & 0.561 & 0.496 \\
\hline Age 65-69 & 0.377 & 0.485 & 0.313 & 0.464 & 0.310 & 0.462 \\
\hline Age $70-74$ & 0.259 & 0.438 & 0.293 & 0.455 & 0.282 & 0.450 \\
\hline Age $75-79$ & 0.205 & 0.404 & 0.196 & 0.397 & 0.213 & 0.409 \\
\hline 1 chronic cond & 0.229 & 0.420 & 0.216 & 0.412 & 0.176 & 0.381 \\
\hline 2 chronic conditions & 0.222 & 0.416 & 0.212 & 0.409 & 0.204 & 0.403 \\
\hline 3 chronic conditions & 0.172 & 0.378 & 0.156 & 0.363 & 0.183 & 0.387 \\
\hline $\begin{array}{l}\text { 4+ chronic conditions } \\
\text { Illness/injury in past } 2\end{array}$ & 0.247 & 0.432 & 0.245 & 0.430 & 0.315 & 0.465 \\
\hline $\begin{array}{l}\text { weeks } \\
\text { Self-ass }\end{array}$ & 0.153 & 0.360 & 0.139 & 0.346 & 0.072 & 0.259 \\
\hline good & 0.242 & 0.429 & 0.301 & 0.459 & 0.241 & 0.427 \\
\hline Self-assessed health-good & 0.276 & 0.447 & 0.333 & 0.471 & 0.320 & 0.466 \\
\hline Self-assessed health-fair & 0.153 & 0.360 & 0.173 & 0.378 & 0.217 & 0.412 \\
\hline Self-assessed health-poor & 0.031 & 0.173 & 0.059 & 0.236 & 0.100 & 0.300 \\
\hline $\begin{array}{l}\text { Education-high school } \\
\text { Education-some post }\end{array}$ & 0.179 & 0.384 & 0.195 & 0.396 & 0.199 & 0.399 \\
\hline $\begin{array}{l}\text { secondary } \\
\text { Education-have a } \\
\text { degree/bachelor, Master, }\end{array}$ & 0.135 & 0.342 & 0.259 & 0.438 & 0.249 & 0.433 \\
\hline PhD & 0.053 & 0.223 & 0.088 & 0.284 & 0.103 & 0.304 \\
\hline Immigrant & 0.272 & 0.445 & 0.275 & 0.446 & 0.405 & 0.491 \\
\hline Working & 0.068 & 0.252 & 0.051 & 0.219 & 0.094 & 0.292 \\
\hline Additional insurance & 0.689 & 0.463 & 0.600 & 0.490 & --- & --- \\
\hline
\end{tabular}


Table 5, Concentration index for observed drug utilization

\begin{tabular}{|c|c|c|c|c|c|c|}
\hline & \multicolumn{2}{|l|}{1990 OHS } & \multicolumn{2}{|l|}{ 1996-97 NPHS } & \multicolumn{2}{|l|}{ 2000-01 CCHS } \\
\hline & $\begin{array}{c}\text { Concentration } \\
\text { Index }\end{array}$ & t-statistics & $\begin{array}{c}\text { Concentration } \\
\text { Index }\end{array}$ & t-statistics & $\begin{array}{l}\text { Concentration } \\
\text { Index }\end{array}$ & t-statistics \\
\hline Senior & -0.0657 & -5.1328 & -0.0094 & -1.1899 & -0.0229 & -2.8272 \\
\hline $\begin{array}{l}\text { Non- } \\
\text { senior }\end{array}$ & -0.0210 & -2.9577 & 0.0108 & 2.5714 & 0.0118 & 3.0256 \\
\hline
\end{tabular}


Table-6, Horizontal Inequity Index

\begin{tabular}{|c|c|c|c|c|c|c|c|}
\hline & & \multicolumn{2}{|l|}{1990 OHS } & \multicolumn{2}{|l|}{ 1996-97 NPHS } & \multicolumn{2}{|l|}{ 2000-01 CCHS } \\
\hline & & $\begin{array}{c}\text { Horizontal } \\
\text { Inequity Index }\end{array}$ & t-statistics & $\begin{array}{c}\text { Horizontal } \\
\text { Inequity Index }\end{array}$ & t-statistics & $\begin{array}{c}\text { Horizontal } \\
\text { Inequity Index }\end{array}$ & t-statistics \\
\hline \multirow[b]{2}{*}{ Probability of drug use } & Senior & -0.0042 & -0.7500 & 0.0019 & 0.6129 & 0.0061 & 3.5882 \\
\hline & $\begin{array}{l}\text { Non- } \\
\text { senior }\end{array}$ & 0.0114 & 2.3750 & 0.0174 & 10.8750 & 0.0187 & 18.7000 \\
\hline \multirow{2}{*}{$\begin{array}{l}\text { Number of drug use } \\
\text { conditional on positive } \\
\text { use }\end{array}$} & Senior & -0.0200 & -1.6667 & 0.0216 & 3.7241 & 0.0178 & 4.0455 \\
\hline & $\begin{array}{l}\text { Non- } \\
\text { senior }\end{array}$ & -0.0466 & -1.9256 & 0.0371 & 9.5128 & 0.0321 & 11.4643 \\
\hline \multirow[b]{2}{*}{$\begin{array}{l}\text { Total number of drug } \\
\text { use }\end{array}$} & Senior & -0.0112 & -1.0667 & 0.0230 & 4.8936 & 0.0208 & 5.4737 \\
\hline & $\begin{array}{l}\text { Non- } \\
\text { senior }\end{array}$ & -0.0074 & -1.1935 & 0.0317 & 11.3214 & 0.0282 & 13.4286 \\
\hline
\end{tabular}


Table-7, Contribution to the income-related inequality in the number of drug use

\begin{tabular}{|c|c|c|c|c|c|c|}
\hline & $\begin{array}{l}\text { Senior } \\
\text { Contribu }\end{array}$ & ttion to Ove & erall $\mathrm{Cl}$ & $\begin{array}{l}\text { Non-s } \\
\text { Contri }\end{array}$ & to $C$ & 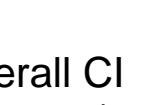 \\
\hline & 1990 & $1996 / 97 \quad 2$ & $0 / 01$ & 1990 & 1996/ & $000 / 01$ \\
\hline come & -0.0083 & 0.0133 & 0.0026 & -0.0023 & 0.0063 & 0.0102 \\
\hline b & 3 & -0.0 & -0.0015 & -0.0030 & -0.0040 & -0.0051 \\
\hline ge & -0.0021 & 0.0001 & 0.0005 & .0176 & -0.0012 & 0.002 \\
\hline & & & & & & \\
\hline injury & $\mid-0.0111$ & -0.0114 & +-0.0194 & 0.0045 & -0.0010 & 0.0003 \\
\hline & -0.0007 & -0.0021 & -0.0008 & 0.0002 & -0.0020 & -0.0018 \\
\hline Hea & -0.0257 & -0.0 & -0.0216 & -0.0187 & -0.01 & -0.013 \\
\hline Edu & 0.0005 & -0.0002 & 0.0025 & -0.0053 & 0.0062 & 0.0054 \\
\hline Statc & & & 0.0037 & 0.0002 & 0.0028 & 0.0082 \\
\hline $\begin{array}{l}\text { Working Status } \\
\text { Additional }\end{array}$ & -0.0020 & -0.0008 & 0.0007 & -0.0075 & -0.0008 & 0.0009 \\
\hline Inst & & & --- & 0.0052 & 0.0077 & --- \\
\hline Err & & & 0.0105 & -0.0119 & 0.0080 & 0.0048 \\
\hline $\mathrm{Cl}$ & -0.0657 & -0.0094 & -0.0229 & -0.0210 & 0.0108 & 0.0118 \\
\hline
\end{tabular}


Figures

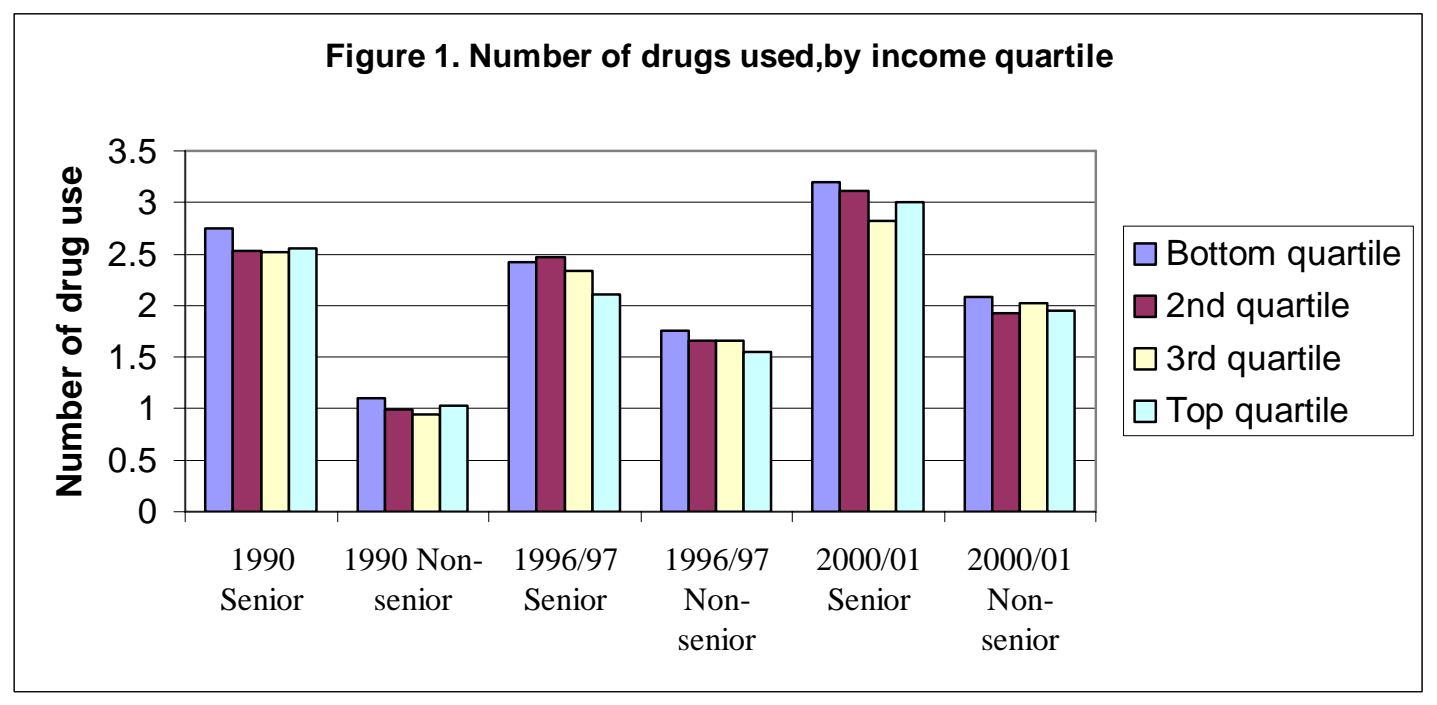




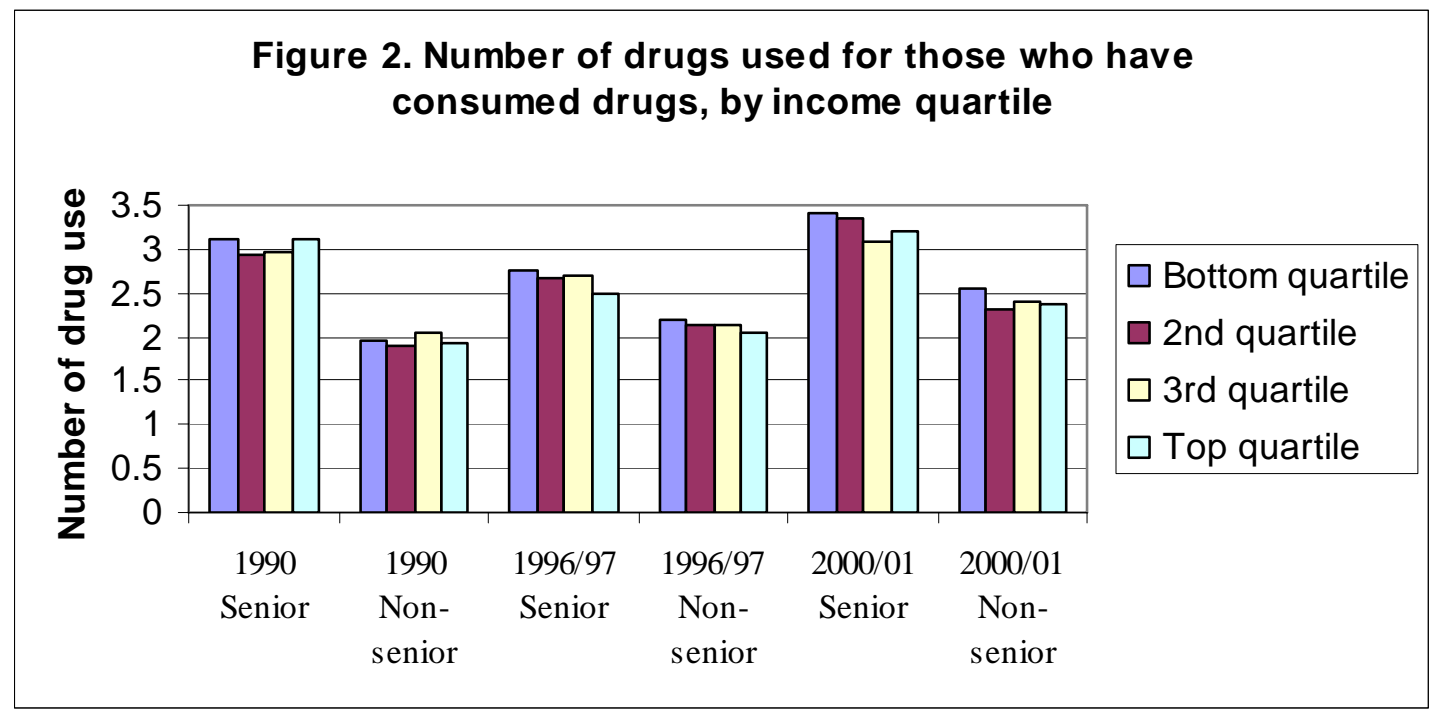




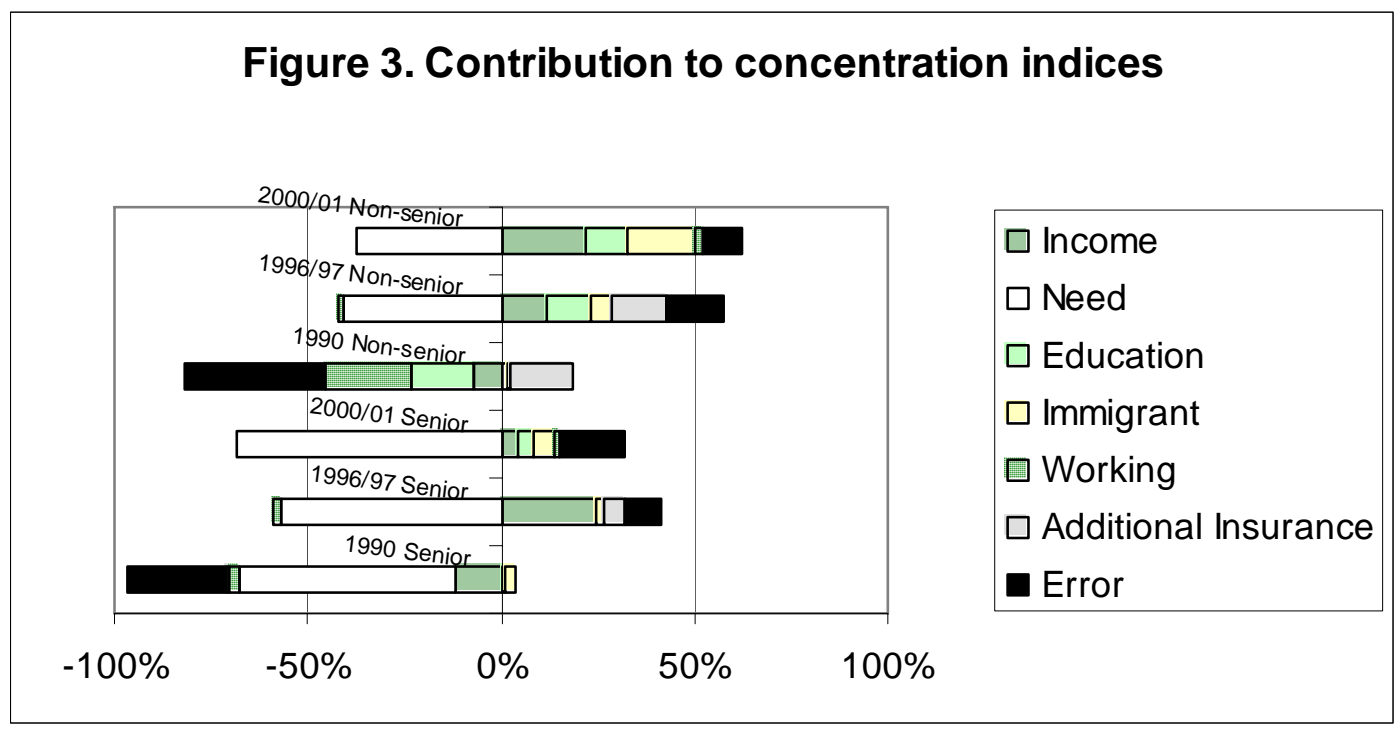

